\title{
Retrial Queuing System with Single Working Vacation under Pre-Emptive Priority Service
}

\author{
G.Ayyappan \\ Pondicherry Engineering College \\ Pondicherry \\ India
}

\author{
A.Muthu Ganapathi \\ Subramanian \\ Tagore Arts College \\ Pondicherry \\ India
}

\author{
Gopal Sekar \\ Tagore Arts College \\ Lawspet \\ Pondicherry \\ India
}

\begin{abstract}
Consider a single server retrial queueing system with preemptive priority service and single working vacation in which two types of customers arrive in a Poisson process with arrival rates $\boldsymbol{\lambda}_{\mathbf{1}}$ for low and $\boldsymbol{\lambda}_{\mathbf{2}}$ for high priority customers. We assume that regular service times follow an exponential distribution with parameters $\boldsymbol{\mu}_{1}$ and $\boldsymbol{\mu}_{2}$ correspondingly. The retrial is introduced for low priority customers only. During working vacation the server serve's the arriving customers with lesser service rates $\boldsymbol{\mu}_{3}$ and $\boldsymbol{\mu}_{\mathbf{4}}$ respectively. These service rates $\boldsymbol{\mu}_{\mathbf{3}}$ and $\boldsymbol{\mu}_{\mathbf{4}}$ follow an exponential distribution. However at any time the server may return from the working vacation with a working vacation rate $\boldsymbol{\alpha}$ which follows the exponential distribution. The access from orbit to the service facility follows the classical retrial policy and the high priority customers will be governed by the pre-emptive priority service. This model is solved by using Matrix geometric Technique. Numerical study have been done in elaborate manner for finding the Mean number of customers in the orbit, Probabilities that server is idle, busy during working vacation and normal period.
\end{abstract}

\section{Keywords}

Single Server - pre-emptive priority service - working vacation Matrix Geometric Method - classical retrial policy

\section{INTRODUCTION}

Queueing systems in which arriving customers who find all servers and waiting positions (if any) occupied may retry for service after a period of time as discussed by Artalejo [1] in his bibliography, is called Retrial queues. Because of the complexity of the retrial queueing models, analytic results are generally difficult to obtain. There are a great number of numerical and approximations methods are available, in this paper we will place more emphasis on the solutions by Matrix geometric method discussed by Gomez [4].

\section{MODEL DESRIPTION}

Consider a single server retrial queueing system with preemptive priority service studied by Choi [2], Falin [3], Ayyappan[5] and single working vacation in which two types of customers arrive in a Poisson process with arrival rate $\lambda_{1}$ for low priority customers and $\lambda_{2}$ for high priority customers. These customers are identified as primary calls. In this model the server provides two types of service rates namely Regular service rates and lesser service rates. The regular service rates follow an exponential distribution with parameters $\mu_{1}$ and $\mu_{2}$ for low and high priority customers respectively. The lesser service rates during the working vacation follows the exponential distribution with parameter $\mu_{3}$ and $\mu_{4}$ for low and high priority customers respectively. The working vacation rate follows an exponential distribution with parameter $\alpha$. The retrial is introduced for low priority customers only. Let $\mathrm{K}$ be the maximum number of waiting spaces for high priority customers in front of the service station.

\subsection{Description of the Working Vacation}

Working vacation models studied by Liu [6], Tian [8], Tien Van Do [9], Wu [10], is a kind of semi-vacation policy and it was first introduced by Servi and Finn [7]. A customer is served at a lesser service rate rather than completely stopping the service during a vacation. Part of service ability keeps the system operating in a lesser speed during a vacation. In the classical vacation queueing models, the server completely stops the service, but under working vacation policy, the server can still work during the vacation. So the working vacation is more reasonable than the classical vacation in some cases. If service speed degenerates into zero in a working vacation, the working vacation queueing model becomes a classical vacation queueing model. Therefore, the working vacation model is the generalization of the classical vacation model. The working vacation period is an operation period with a lower speed. At a vacation completion instant, if there are customers in the system, the server will come back to the normal working level. Otherwise, the server stays in an idle period. Once customers arrive into the system the server immediately begins a new busy period. After completion of a service (low/high), the server has to go for compulsory working vacation provided all the conditions below are satisfied.

1. There are no customers in the service station,

2. There are no customers in the high priority queue and

3. There are no customers (low priority) in the orbit 
This is called a single working vacation policy (Exhaustive service type). The server may return from the working vacation at any time and is independent of the number of customers in the system. The term Single working vacation means the server goes for another working vacation again after completing atleast one service. Assume that the service time's $\boldsymbol{\mu}_{3}, \boldsymbol{\mu}_{4}$ during the working vacation are lesser than $\boldsymbol{\mu}_{1}, \boldsymbol{\mu}_{\mathbf{2}}$ respectively.

If the server is free at the time of a primary call (low/high), the arriving call begins to be served immediately by the server and customer leaves the system after service completion. Otherwise, if the server is busy then the low priority arriving customer goes to orbit and becomes a source of repeated calls. The pool of sources of repeated calls may be viewed as a sort of queue. Every such source produces a Poisson process of repeated calls with intensity $\boldsymbol{\sigma}$. If an incoming repeated call (low) finds the server free, it is served and leaves the system after service, while the source which produced this repeated call disappears. If any one of the waiting spaces is occupied by the high priority customers then the low priority customers (as a primary call) cannot enter into the service station and goes to the orbit. If the server is busy and there are some waiting spaces then a high priority customer can enter into the service station and waits for his service. If there are no waiting spaces then the high priority customers cannot enter into the service station and will be lost for the system. Otherwise, the system state does not change.

\subsection{Priority Rule}

If the server is engaging with low priority customer and at that time the higher priority customer enters then the high priority customer will get service immediately and the low priority customer who is in service goes to orbit without completion of his service. This type of priority service is called the Pre-emptive priority service.

\subsection{Retrial Policy:}

Most of the queueing system with repeated attempts assume that each customer in the retrial group seeks service independently of each other after a random time exponentially distributed with rate $\boldsymbol{\sigma}$ so that the probability of repeated attempt during the interval $(t, t+\Delta \mathrm{t})$ given that there were $\mathrm{n}$ customers in orbit at time $t$ is $\mathbf{n} \boldsymbol{\sigma} \Delta \mathbf{t}+$ $\mathbf{O}(\Delta \mathbf{t})$. This discipline for access for the server from the retrial group is called classical retrial rate policy. The input flow of primary calls (low and high), interval between repetitions and service times are mutually independent.

\section{MATRIX GEOMETRIC METHOD}

Let $\mathrm{N}(\mathrm{t})$ be the random variable which represents the number of low priority customers in the orbit at time $t$ and $\mathrm{H}(\mathrm{t})$ be the random variable which represents the number of high priority customers in the queue (in front of the service station) at time $t$ and $\mathrm{S}(\mathrm{t})$ represents the server state at time $\mathrm{t}$ and $\mathrm{C}(\mathrm{t})$ represents working vacation period of system at time $t$. The random process is described as

$\{<\mathrm{N}(\mathrm{t}), \mathrm{H}(\mathrm{t}), \mathrm{S}(\mathrm{t}), \mathrm{C}(\mathrm{t})\rangle / \mathrm{N}(\mathrm{t})=0,1,2,3, \ldots ; \mathrm{H}(\mathrm{t})=0,1,2,3, \ldots, \mathrm{k} ;$ $\mathrm{S}(\mathrm{t})=0,1,2 ; \mathrm{C}(\mathrm{t})=0,1\}$.

$\mathrm{S}(\mathrm{t})=0$ if the server is idle at time $\mathrm{t}$

$\mathrm{S}(\mathrm{t})=1$ if the server busy with low priority customer at time $\mathrm{t}$
$\mathrm{S}(\mathrm{t})=2$ if the server busy with high priority customer at time $\mathrm{t}$

$\mathrm{C}(\mathrm{t})=0$ if the server is in working vacation at time $\mathrm{t}$

$\mathrm{C}(\mathrm{t})=1$ if the server is in normal level at time $\mathrm{t}$.

The possible state spaces are

$\{(\mathrm{u}, \mathrm{v}, \mathrm{w}, \mathrm{z}): \mathrm{u}=0,1,2,3, \ldots ; \mathrm{v}=0 ; \mathrm{w}=0,1,2 ; \mathrm{z}=0\} \mathrm{U}$

$\{(\mathrm{u}, \mathrm{v}, \mathrm{w}, \mathrm{z}): \mathrm{u}=0,1,2,3, \ldots ; \mathrm{v}=1,2,3, \ldots, \mathrm{k} ; \mathrm{w}=2 ; \mathrm{z}=0\} \mathrm{U}$

$\{(\mathrm{u}, \mathrm{v}, \mathrm{w}, \mathrm{z}): \mathrm{u}=0,1,2,3, \ldots ; \mathrm{v}=0 ; \mathrm{w}=0,1,2 ; \mathrm{z}=1\} \mathrm{U}$

$\{(\mathrm{u}, \mathrm{v}, \mathrm{w}, \mathrm{z}): \mathrm{u}=0,1,2,3, \ldots ; \mathrm{v}=1,2,3, \ldots, \mathrm{k} ; \mathrm{w}=2 ; \mathrm{z}=1\}$

The infinitesimal generator matrix $\mathbf{Q}$ is given below

$$
Q=\left(\begin{array}{llllll}
\mathrm{A}_{00} & \mathrm{~A}_{0} & \mathrm{O} & \mathrm{O} & \mathrm{O} & \ldots \\
\mathrm{A}_{10} & \mathrm{~A}_{11} & \mathrm{~A}_{0} & \mathrm{O} & \mathrm{O} & \ldots \\
\mathrm{O} & \mathrm{A}_{21} & \mathrm{~A}_{22} & \mathrm{~A}_{0} & \mathrm{O} & \cdots \\
\mathrm{O} & \mathrm{O} & \mathrm{A}_{32} & \mathrm{~A}_{33} & \mathrm{~A}_{0} & \cdots \\
\cdots & \cdots & \cdots & \cdots & \cdots & \cdots
\end{array}\right)
$$

Notations

$$
\begin{array}{lll}
\mathrm{T}_{1}=-\left(\lambda_{1}+\lambda_{2}+\alpha\right) & \mathrm{T}_{2}=-\left(\lambda_{1}+\lambda_{2}+\mu_{3}+\alpha\right) & \mathrm{T}_{3}=-\left(\lambda_{1}+\lambda_{2}+\mu_{4}+\alpha\right) \\
\mathrm{T}_{5}=-\left(\lambda_{1}+\mu_{4}+\alpha\right) & \mathrm{T}_{6}=-\left(\mathrm{n} \sigma+\lambda_{1}+\lambda_{2}+\alpha\right) & \mathrm{T}_{7}=-\left(\mathrm{M} \sigma+\lambda_{1}+\lambda_{2}+\alpha\right) \\
\mathrm{T}_{8}=-\left(\mu_{3}+\alpha\right) & \mathrm{T}_{9}=-\left(\lambda_{2}+\mu_{4}+\alpha\right) & \mathrm{T}_{11}=-\left(\mu_{4}+\alpha\right) \\
\mathrm{S}_{1}=-\left(\lambda_{1}+\lambda_{2}\right) & \mathrm{S}_{2}=-\left(\lambda_{1}+\lambda_{2}+\mu_{1}\right) & \mathrm{S}_{3}=-\left(\lambda_{1}+\lambda_{2}+\mu_{2}\right) \\
\mathrm{S}_{5}=-\left(\lambda_{1}+\mu_{2}\right) & \mathrm{S}_{6}=-\left(\mathrm{n} \sigma+\lambda_{1}+\lambda_{2}\right) & \mathrm{S}_{7}=-\left(\mathrm{M} \sigma+\lambda_{1}+\lambda_{2}\right) \\
\mathrm{S}_{8}=-\left(\mu_{1}\right) & \mathrm{S}_{9}=-\left(\lambda_{2}+\mu_{2}\right) & \mathrm{S}_{11}=-\left(\mu_{2}\right)
\end{array}
$$

$\mathbf{A}_{00}, \mathbf{A}_{\mathrm{nn}-\mathbf{1}}, \mathbf{A}_{\mathrm{nn}}, \mathbf{A}_{\mathrm{nn}+\mathbf{1}}$ are square matrices order $(2 \mathrm{k}+6)$.

The matrix $\mathrm{A}_{00}$ is described as

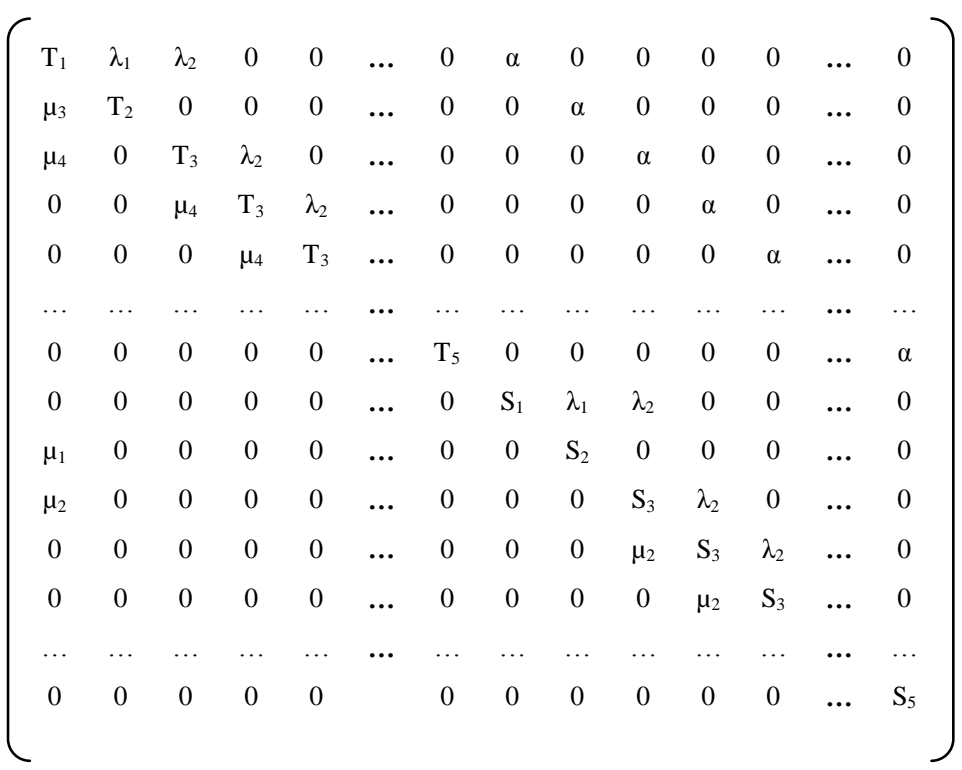




$$
\mathbf{A}_{\mathrm{n}, \mathrm{n}-\mathbf{1}}=\left(\mathbf{a}_{\mathrm{ij}}\right)
$$

where $a_{i j}=n \sigma$ if $(i=1$ and $j=2),(i=k+4$ and $j=k+5)$

$$
=0 \quad \text { otherwise }
$$

$$
\begin{aligned}
& \mathbf{A}_{\mathbf{n}, \mathbf{n}+\mathbf{1}}=\left(\mathbf{a}_{\mathbf{i j}}\right) \text { where } \mathbf{a}_{\mathbf{i j}}=\lambda_{1} \quad \text { if } \mathrm{i}=\mathrm{j} \text { and } \mathrm{i}=2,3,4, \ldots, 2 \mathrm{k}+6 \\
& =\lambda_{2} \text { if } \mathrm{i}=2 \text { and } \mathrm{j}=3 \\
& =0 \text { otherwise. }
\end{aligned}
$$

The matrix $A_{n n}$ is described as

$$
\left(\begin{array}{cccccccccccccc}
\mathrm{T}_{6} & \lambda_{1} & \lambda_{2} & 0 & 0 & . & 0 & \alpha & 0 & 0 & 0 & 0 & . & 0 \\
\mu_{3} & \mathrm{~T}_{2} & 0 & 0 & 0 & . & 0 & 0 & \alpha & 0 & 0 & 0 & . & 0 \\
\mu_{4} & 0 & \mathrm{~T}_{3} & \lambda_{2} & 0 & . & 0 & 0 & 0 & \alpha & 0 & 0 & . & 0 \\
0 & 0 & \mu_{4} & \mathrm{~T}_{3} & \lambda_{2} & . & 0 & 0 & 0 & 0 & \alpha & 0 & . & 0 \\
0 & 0 & 0 & \mu_{4} & \mathrm{~T}_{3} & . & 0 & 0 & 0 & 0 & 0 & \alpha & . & 0 \\
. . & . . & . . & . . & . . & . & . . & . . & . . & . . & . . & . . & . & . . \\
0 & 0 & 0 & 0 & 0 & . & \mathrm{T}_{5} & 0 & 0 & 0 & 0 & 0 & . & \alpha \\
0 & 0 & 0 & 0 & 0 & . & 0 & \mathrm{~S}_{6} & \lambda_{1} & \lambda_{2} & 0 & 0 & . & 0 \\
0 & 0 & 0 & 0 & 0 & . & 0 & \mu_{1} & \mathrm{~S}_{2} & 0 & 0 & 0 & . & 0 \\
0 & 0 & 0 & 0 & 0 & . & 0 & \mu_{2} & 0 & \mathrm{~S}_{3} & \lambda_{2} & 0 & . & 0 \\
0 & 0 & 0 & 0 & 0 & . & 0 & 0 & 0 & \mu_{2} & \mathrm{~S}_{3} & \lambda_{2} & . & 0 \\
0 & 0 & 0 & 0 & 0 & . & 0 & 0 & 0 & 0 & \mu_{2} & \mathrm{~S}_{3} & . & 0 \\
. . & . . & . . & . . & . . & . & . . & . . & . . & . . & . . & . . & . & . . \\
0 & 0 & 0 & 0 & 0 & . & 0 & 0 & 0 & 0 & 0 & 0 & . & \mathrm{S}_{5}
\end{array}\right)
$$

If the capacity of the orbit is finite say $M$ then $A_{M M}$ is described as

$$
\left(\begin{array}{lllllllllllll}
\mathrm{T}_{7} & \lambda_{1} & \lambda_{2} & 0 & 0 & . & 0 & \alpha & 0 & 0 & 0 & 0 & . \\
\mu_{3} & \mathrm{~T}_{8} & 0 & 0 & 0 & . & 0 & 0 & \alpha & 0 & 0 & 0 & . \\
\mu_{4} & 0 & \mathrm{~T}_{9} & \lambda_{2} & 0 & . & 0 & 0 & 0 & \alpha & 0 & 0 & . \\
0 & 0 & \mu_{4} & \mathrm{~T}_{9} & \lambda_{2} & . & 0 & 0 & 0 & 0 & \alpha & 0 & . \\
0 & 0 & 0 & \mu_{4} & \mathrm{~T}_{9} & . & 0 & 0 & 0 & 0 & 0 & \alpha & . \\
. . & . . & . . & . . & . & . & . . & . . & . . & . . & . . & . . & . \\
0 & 0 & 0 & 0 & 0 & . & \mathrm{T}_{11} & 0 & 0 & 0 & 0 & 0 & . \\
0 & 0 & 0 & 0 & 0 & . & 0 & \mathrm{~S}_{7} & \lambda_{1} & \lambda_{2} & 0 & 0 & . \\
0 & 0 & 0 & 0 & 0 & . & 0 & 0 & \mathrm{~S}_{8} & 0 & 0 & 0 & . \\
0 & 0 & 0 & 0 & 0 & . & 0 & 0 & 0 & \mathrm{~S}_{9} & \lambda_{2} & 0 & . \\
0 & 0 & 0 & 0 & 0 & . & 0 & 0 & 0 & \mu_{2} & \mathrm{~S}_{9} & \lambda_{2} & . \\
0 & 0 & 0 & 0 & 0 & . & 0 & 0 & 0 & 0 & \mu_{2} & \mathrm{~S}_{9} & . \\
. . & . . & . . & . . & . . & . & . . & . . & . . & . . & . . & . . & . \\
0 & 0 & 0 & 0 & 0 & . & 0 & 0 & 0 & 0 & 0 & 0 & . \\
. & & & & & & & & & & & &
\end{array} .\right.
$$

Let $\mathbf{X}$ be a steady-state probability vector of Q and partitioned as $\mathbf{X}=(\mathrm{x}(0), \mathrm{x}(1), \mathrm{x}(2), \ldots)$ and $\mathbf{X}$ satisfies

$$
\mathbf{X Q}=\mathbf{0}, \quad \mathrm{Xe}=\mathbf{1}
$$

where $x(\mathrm{i})=\left(\mathrm{P}_{\mathrm{i} 000}, \mathrm{P}_{\mathrm{i} 010}, \mathrm{P}_{\mathrm{i} 020}, \mathrm{P}_{\mathrm{i} 120}, \mathrm{P}_{\mathrm{i} 220}, \ldots, \mathrm{P}_{\mathrm{i} k 20}, \mathrm{P}_{\mathrm{i} 001}, \mathrm{P}_{\mathrm{i} 011}, \mathrm{P}_{\mathrm{i} 021}\right.$,

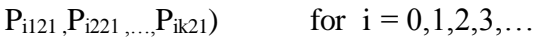

\section{DIRECT TRUNCATION METHOD}

In this method one can truncate the system of equations in (1) for sufficiently large value of the number of customers in the orbit, say $M$. That is, the orbit size is restricted to $M$ such that any arriving customer finding the orbit full is considered lost. The value of $\mathrm{M}$ can be chosen so that the loss probability is small. Due to the intrinsic nature of the system in (1) the only choice available for studying $\mathrm{M}$ is through algorithmic methods. While a number of approaches are available for determining the cut-off point, $\mathrm{M}$, the one that seems to perform well (with respect to approximating the system performance measures) is to increase $\mathbf{M}$ until the largest individual change in the elements of $\mathbf{X}$ for successive values is less than $\boldsymbol{\varepsilon}$ a predetermined infinitesimal value.

\section{ANALYSIS OF STEADY STATE PROBABILITIES}

We are applying Direct Truncation Method to find Steady state probability vector $\mathbf{X}$. Let $\mathbf{M}$ denote the cut-off point or Truncation level. The steady state probability vector $\mathbf{X}^{(\mathbf{M})}$ is now partitioned as $\mathbf{X}^{(\mathbf{M})}=(\mathrm{x}(0), \mathrm{x}(1), \mathrm{x}(2), \ldots . \mathrm{x}(\mathbf{M}))$ and $\mathbf{X}^{(\mathbf{M})}$ satisfies

$$
\mathbf{X}^{(M)} \mathbf{Q}=\mathbf{0}, \mathbf{X}^{(M)} \mathbf{e}=\mathbf{1}
$$

where $x(\mathrm{i})=\left(\mathrm{P}_{\mathrm{i} 000}, \mathrm{P}_{\mathrm{i} 010}, \mathrm{P}_{\mathrm{i} 020}, \mathrm{P}_{\mathrm{i} 120}, \mathrm{P}_{\mathrm{i} 220, \ldots,} \mathrm{P}_{\mathrm{i} 202}, \mathrm{P}_{\mathrm{i} 001}, \mathrm{P}_{\mathrm{i} 011}, \mathrm{P}_{\mathrm{i} 021}\right.$, $\mathrm{P}_{\mathrm{i} 121}, \mathrm{P}_{\left.\mathrm{i} 221, \ldots, \mathrm{P}_{\mathrm{ik} 21}\right)}$ for $\mathrm{i}=0,1,2,3, \ldots, \mathrm{M}$

The above system of equations is solved by Numerical method such as GAUSS-JORDAN elementary transformation method. Since there is no clear cut choice for $M$, we may start the iterative process by taking, say $M=1$ and increase it until the individual elements of $\mathbf{X}$ do not change significantly. That is, if $\mathrm{M}^{*}$ denotes the truncation point then

$$
\left\|\mathbf{X}^{\mathbf{M}^{*}}(\mathbf{i})-\mathbf{X}^{\mathbf{M}^{*-1}}(\mathbf{i})\right\|_{\infty}<\boldsymbol{\varepsilon}, \boldsymbol{\varepsilon} \text { is an infinitesimal quantity. }
$$

\section{STABILITY CONDITION}

Theorem : The inequality $\frac{\lambda_{1}}{\mu_{1}}<F^{-1}$ where $\mathrm{x}=\lambda_{2} / \mu_{2}$ is the

necessary and sufficient condition for the system to be stable.

Proof:

Let $\mathrm{Q}$ be an infinitesimal generator matrix for the queueing system (without retrial)

$S_{11}$ The stationary probability vector $\mathrm{X}$ satisfying

$$
\mathbf{X Q}=\mathbf{0} \text { and } \mathbf{X e}=\mathbf{1}
$$


$\mathbf{A}_{0}+\mathbf{R} \mathbf{A}_{1}+\mathbf{R}^{\mathbf{2}} \mathbf{A}_{2}=\mathbf{0}, \mathbf{R}$ is the Rate Matrix

The system is stable if $\mathrm{sp}(\mathrm{R})<1$

$\mathrm{R}$ satisfies $\mathrm{sp}(\mathrm{R})<1$ if and only if $\boldsymbol{\Pi A}_{\mathbf{0}} \mathbf{e}<\boldsymbol{\Pi \mathbf { A } _ { 2 }} \mathbf{e}$

where $\Pi$ is given by $\left(\pi_{0}, \pi_{1}, \pi_{2}, \ldots, \pi_{k}, \pi_{k+1}, \chi_{0}, \chi_{1}, \chi_{2}, \ldots\right.$ $\left., \chi_{k}, \chi_{k+1}\right)$

$$
\begin{aligned}
& \Pi A=0 \text { and } \Pi e=1 \\
& A=A_{0}+A_{1}+A_{2}
\end{aligned}
$$

$\mathrm{A}_{0}, \mathrm{~A}_{1}, \mathrm{~A}_{2}$ are square matrices of order $2 \mathrm{k}+4$ and

$\mathrm{A}_{0}=\lambda_{1} \mathrm{I}$ where I an identity matrix

The matrix $A_{1}$ is described as

$$
\left(\begin{array}{cccccccccccc}
\mathrm{T}_{2} & 0 & 0 & 0 & \cdots & 0 & \alpha & 0 & 0 & 0 & \cdots & 0 \\
0 & \mathrm{~T}_{3} & \lambda_{2} & 0 & \cdots & 0 & 0 & \alpha & 0 & 0 & \cdots & 0 \\
0 & \mu_{4} & \mathrm{~T}_{3} & \lambda_{2} & \cdots & 0 & 0 & 0 & \alpha & 0 & \cdots & 0 \\
0 & 0 & \mu_{4} & \mathrm{~T}_{3} & \cdots & 0 & 0 & 0 & 0 & \alpha & \cdots & 0 \\
\cdots & \cdots & \cdots & \ldots & \cdots & \cdots & \cdots & \cdots & \cdots & \cdots & \cdots & \cdots \\
0 & 0 & 0 & 0 & \cdots & \mathrm{T}_{5} & 0 & 0 & 0 & 0 & \cdots & \alpha \\
0 & 0 & 0 & 0 & \cdots & 0 & \mathrm{~S}_{2} & 0 & 0 & 0 & \cdots & 0 \\
0 & 0 & 0 & 0 & \cdots & 0 & 0 & \mathrm{~S}_{3} & \lambda_{2} & 0 & \cdots & 0 \\
0 & 0 & 0 & 0 & \cdots & 0 & 0 & \mu_{2} & \mathrm{~S}_{3} & \lambda_{2} & \cdots & 0 \\
0 & 0 & 0 & 0 & \cdots & 0 & 0 & 0 & \mu_{2} & \mathrm{~S}_{3} & \cdots & 0 \\
\cdots & \cdots & \cdots & \cdots & \cdots & \cdots & \cdots & \cdots & \cdots & \cdots & \cdots & \cdots \\
0 & 0 & 0 & 0 & & 0 & 0 & 0 & 0 & 0 & \cdots & \mathrm{S}_{5}
\end{array}\right)
$$

$$
\begin{aligned}
& A_{2}=\left(a_{i j}\right) \quad \text { Where } \quad a_{i j}=\mu_{3} \text { if } i=1 \text { and } j=1 \\
& a_{i j}=\mu_{4} \text { if } i=2 \text { and } j=1 \\
& \mathrm{a}_{\mathrm{ij}}=0 \text { otherwise }
\end{aligned}
$$

By substituting $\mathrm{A}_{0}, \mathrm{~A}_{1}, \mathrm{~A}_{2}$ in equation (5) and (6)

$$
\begin{aligned}
& -\left(\lambda_{2}+\alpha\right) \pi_{0}+\mu_{4} \pi_{1}=0 \\
& \lambda_{2} \pi_{0}-\left(\lambda_{2}+\mu_{4}+\alpha\right) \pi_{1}+\mu_{4} \pi_{2}=0 \\
& \lambda_{2} \pi_{1}-\left(\lambda_{2}+\mu_{4}+\alpha\right) \pi_{2}+\mu_{4} \pi_{3}=0 \\
& \lambda_{2} \pi_{2}-\left(\lambda_{2}+\mu_{4}+\alpha\right) \pi_{3}+\mu_{4} \pi_{4}=0 \\
& \lambda_{2} \pi_{3}-\left(\lambda_{2}+\mu_{4}+\alpha\right) \pi_{4}+\mu_{4} \pi_{5}=0 \\
& \quad \ldots \ldots \\
& \lambda_{2} \pi_{\mathrm{k}-1}-\left(\lambda_{2}+\mu_{4}+\alpha\right) \pi_{\mathrm{k}}+\mu_{4} \pi_{\mathrm{k}+1}=0 \\
& \lambda_{2} \pi_{\mathrm{k}}-\left(\mu_{4}+\alpha\right) \pi_{\mathrm{k}+1}=0 \\
& \alpha \pi_{0}-\lambda_{2} \chi_{0}+\mu_{2} \chi_{1}=0 \\
& \alpha \pi_{1}+\lambda_{2} \chi_{0}-\left(\lambda_{2}+\mu_{2}\right) \chi_{1}+\mu_{2} \chi_{2}=0 \\
& \alpha \pi_{2}+\lambda_{2} \chi_{1}-\left(\lambda_{2}+\mu_{2}\right) \chi_{2}+\mu_{2} \chi_{3}=0 \\
& \alpha \pi_{3}+\lambda_{2} \chi_{2}-\left(\lambda_{2}+\mu_{2}\right) \chi_{3}+\mu_{2} \chi_{4}=0 \\
& \alpha \pi_{4}+\lambda_{2} \chi_{3}-\left(\lambda_{2}+\mu_{2}\right) \chi_{4}+\mu_{2} \chi_{5}=0 \\
& \quad \ldots \ldots \\
& \alpha \pi_{\mathrm{k}}+\lambda_{2} \chi_{\mathrm{k}-1}-\left(\lambda_{2}+\mu_{2}\right) \chi_{\mathrm{k}}+\mu_{2} \chi_{\mathrm{k}+1}=0
\end{aligned}
$$

$$
\alpha \pi_{\mathrm{k}+1}+\lambda_{2} \chi_{\mathrm{k}}-\mu_{2} \chi_{\mathrm{k}+1}=0
$$

After Simplification of the above equations, we get

$$
\alpha\left(\pi_{0}+\pi_{1}+\ldots+\pi_{\mathrm{k}+1}\right)=0
$$

Therefore, $\pi_{0}=\pi_{1}=\ldots=\pi_{\mathrm{k}+1}=0$ since $\alpha \neq 0$, further we get,

$$
\chi_{i+1}=\left(\lambda_{2} / \mu_{2}\right) \chi_{i} \quad(i=0,1,2,3, \ldots, k)
$$

From (5)

$$
\begin{aligned}
& \pi_{0}+\pi_{1}+\pi_{2}+\pi_{3}+\pi_{4}+\pi_{5}+\ldots+\pi_{\mathrm{k}-1}+\pi_{\mathrm{k}}+\pi_{\mathrm{k}+1}+\chi_{0}+\chi_{1}+ \\
& \chi_{2}+\chi_{3}+\chi_{4}+\chi_{5}+\ldots+\chi_{\mathrm{k}-1}+\chi_{\mathrm{k}}+\chi_{\mathrm{k}+1}=1
\end{aligned}
$$

by substituting values of $\pi_{\mathrm{i}}$ and $\chi_{\mathrm{i}}$ in the above equation we get

$$
\chi_{0}=F^{-1} \text { where } \mathbf{F}=1+x+x^{2}+\ldots+x^{k+1}, x=\lambda_{2} / \mu_{2}
$$

From (3) $\left(\lambda_{1} / \mu_{1}\right)<\chi_{0}$

by substituting $\chi_{0}$ we get

$$
\left(\lambda_{1} / \mu_{1}\right)<\mathrm{F}^{-1}
$$

The inequality (7) is also a sufficient condition for the retrial queueing system to be stable. Let $\mathrm{Q}_{\mathrm{n}}$ be the number of customers in the orbit after departure $\mathrm{n}^{\text {th }}$ customer from the service station. We first prove the embedded Markov chain $\left\{Q_{n}, n \geq 0\right\}$ is ergodic if (7) satisfies and it is readily to see that $\left\{Q_{n}, n \geq 0\right\}$ is irreducible and aperiodic. It remains to be proved that $\left\{Q_{n}, n \geq\right.$ $0\}$ is positive recurrent. The irreducible and aperiodic Markov chain $\left\{Q_{n}, n \geq 0\right\}$ is positive recurrent if $\left|\psi_{k}\right|<\infty$ for all $k$ and $\lim _{\mathrm{k} \rightarrow \infty} \sup \psi_{\mathrm{k}}<0$ where

$$
\begin{aligned}
& \boldsymbol{\psi}_{\mathbf{k}}=\mathbf{E}\left(\mathbf{Q}_{\mathbf{n}+\mathbf{1}}-\mathbf{Q}_{\mathbf{n}} / \mathbf{Q}_{\mathbf{n}}=\mathbf{k}\right), \mathrm{k}=0,1,2,3,4,5, \ldots \\
& \boldsymbol{\psi}_{\mathbf{k}}=\left(\mathrm{F} \lambda_{1} / \mu_{1}\right)-\mathrm{k} \sigma /\left(\lambda_{1}+\lambda_{2}+\mathrm{k} \sigma\right)
\end{aligned}
$$

if $\left(\mathrm{F} \lambda_{1} / \mu_{1}\right)<1$, then $\left|\psi_{\mathrm{k}}\right|<\infty$ for all $\mathrm{k}$ and $\lim _{\mathrm{k} \rightarrow \infty}$ sup $\psi_{\mathrm{k}}$ $<0$. Therefore the embedded Markov chain $\left\{Q_{n}, n>0\right\}$ is ergodic. If $\mathrm{K} \rightarrow \infty$ then the above stability condition becomes $\left(\lambda_{1} / \mu_{1}+\lambda_{2} / \mu_{2}\right)<1$.

\section{SPECIAL CASES}

1. This model becomes Single Server Retrial queueing system with pre-emptive priority service if $\boldsymbol{\mu}_{1}=\boldsymbol{\mu}_{3}$ and $\boldsymbol{\mu}_{2}=\boldsymbol{\mu}_{4}$

2. This model becomes Single server Retrial queueing system with pre-emptive priority service if $\boldsymbol{\alpha} \rightarrow \infty$.

3. This model becomes Single server Retrial queueing system with exhaustive type classical vacation under pre-emptive priority service as studied by Ayyappan [5] if $\boldsymbol{\mu}_{\mathbf{3}} \rightarrow \mathbf{0}$ and $\boldsymbol{\mu}_{4} \rightarrow \mathbf{0}$.

\section{SYSTEM PERFORMANCE MEASURES}

We can find various probabilities for various values of $\boldsymbol{\lambda}_{\mathbf{1}}, \boldsymbol{\lambda}_{\mathbf{2}}, \boldsymbol{\mu}_{\mathbf{1}}$, $\boldsymbol{\mu}_{\mathbf{2}}, \boldsymbol{\mu}_{\mathbf{3}}, \boldsymbol{\mu}_{\mathbf{4}}, \boldsymbol{\alpha}, \boldsymbol{\sigma}$ and $\mathbf{K}$ and the following system measures can be easily study with these probabilities. The following abbreviations are used in this model.

MNCO : Mean Number of Customers in the Orbit

MPQL : Mean Number of high priority customers in front of the service station 
$\mathrm{P}_{00} \quad$ : Probability that the server is idle during the working vacation

$\mathrm{P}_{10} \quad$ : Probability that the server is busy with low priority customers during the working vacation

$\mathrm{P}_{20} \quad$ : Probability that the server is busy with high priority customers during the working vacation

$\mathrm{P}_{01} \quad$ : Probability that the server is idle in normal period

$\mathrm{P}_{11} \quad$ : Probability that the server is busy with low priority customers during the normal period

$\mathrm{P}_{21} \quad$ : Probability that the server is busy with high priority customers during the normal period

a. The probability mass function of server state during the working vacation

Prob $($ The server is idle $)=\sum_{i=0}^{\infty} p(i, 0,0,0)$

Prob (The server is busy with low priority customer)

$$
=\sum_{i=0}^{\infty} p(i, 0,1,0)
$$

Prob (The server is busy with high priority customer)

$$
=\sum_{i=0}^{\infty} \sum_{j=0}^{k} p(i, j, 2,0)
$$

b. The probability mass function of server state during normal period

Prob (The server is idle) $=\sum_{i=0}^{\infty} p(i, 0,0,1)$

Prob (The server is busy with low priority customer)

$$
=\sum_{i=0}^{\infty} p(i, 0,1,1)
$$

Prob (The server is busy with high priority customer)

$$
=\sum_{i=0}^{\infty} \sum_{j=0}^{k} p(i, j, 2,1)
$$

\section{c. The probability mass function of number of customers}

(low) in the orbit

$$
\begin{aligned}
& \text { Prob (no customers in the orbit) }=\sum_{j=0}^{k} \sum_{m=0}^{1} p(0, j, 2, m)+ \\
& \mathrm{p}(0,0,0,0)+\mathrm{p}(0,0,0,1)+\mathrm{p}(0,0,1,0)+\mathrm{p}(0,0,1,1) \\
& \text { Prob ( i customers in the orbit) }=\sum_{j=0}^{k} \sum_{m=0}^{1} p(i, j, 2, m)+ \\
& \mathrm{p}(\mathrm{i}, 0,0,0)+\mathrm{p}(\mathrm{i}, 0,0,1)+\mathrm{p}(\mathrm{i}, 0,1,0)
\end{aligned}
$$

d. The Probability mass function of number of high priority customers in the queue.

$\mathrm{P}$ (No customers in the high priority queue)

$$
=\sum_{i=0}^{\infty} \sum_{l=0}^{2} \sum_{m=0}^{1} p(i, 0, l, m)
$$

Prob ( $\mathrm{j}$ customers in the high priority queue)

$$
=\sum_{i=0}^{\infty} \sum_{m=0}^{1} p(i, j, 2, m)
$$

e. The Mean number of high priority customers in the queue

$$
\mathrm{MNHP}=\sum_{j=1}^{k} j\left(\sum_{i=0}^{\infty} \sum_{m=0}^{1} p(i, j, 2, m)\right)
$$

f. The Mean number of low priority customers in the orbit

$$
\begin{aligned}
& \mathrm{MNCO}=\left(\sum _ { i = 0 } ^ { \infty } i \left(\sum_{j=0}^{k} \sum_{m=0}^{1} p(i, j, 2, m)+\mathbf{p}(\mathbf{i}, \mathbf{0}, \mathbf{0}, \mathbf{0})+\right.\right. \\
& \mathbf{p}(\mathbf{i}, \mathbf{0}, \mathbf{0}, \mathbf{1})+\mathbf{p}(\mathbf{i}, \mathbf{0}, \mathbf{1}, \mathbf{0})+\mathbf{p}(\mathbf{i}, \mathbf{0}, \mathbf{1}, \mathbf{1}))
\end{aligned}
$$

g. The probability that the orbiting customer (low) is

blocked Blocking Probability

$$
=\sum_{i=1}^{\infty} \sum_{j=0}^{k} \sum_{m=0}^{1} p(i, j, 2, m)+\sum_{i=1}^{\infty} \sum_{m=0}^{1} p(i, 0,1, m)
$$

\section{NUMERICAL STUDY}

Table I, Table II, Table III, Table IV show the impact of retrial rate over the system. Mean number of customers in the orbit decreases as $\sigma$ increases. When $\sigma$ is large, values of tables show that this retrial model becomes standard queueing model. Mean number high priority customers (MPQL) increases as $\mathrm{k}$ increases

Table $\mathrm{V}$ and Table VI show the effect of working vacation rate over the system. As working vacation rate $\alpha$ increase, mean number of customers in the orbit decreases and this model becomes retrial queueing system with pre-emptive priority service.

Table I: Mean number of customers in the orbit and Mean queue length of high Priority queue for $\lambda_{1}=10 \quad \lambda_{2}=5 \quad \mu_{1}=20$ $\mu_{2}=25 \quad \mu_{3}=2 \quad \mu_{4}=5 \quad \sigma=100 \quad k=2$ and $\alpha=100$ and various values of $\sigma$

\begin{tabular}{|c|c|c|c|c|c|c|c|c|}
\hline $\boldsymbol{\sigma}$ & $\mathbf{P}_{\mathbf{0 0}}$ & $\mathbf{P}_{\mathbf{1 0}}$ & $\mathbf{P}_{\mathbf{2 0}}$ & $\mathbf{P}_{\mathbf{0 1}}$ & $\mathbf{P}_{\mathbf{1 1}}$ & $\mathbf{P}_{\mathbf{2 1}}$ & $\mathbf{M N C O}$ & $\mathbf{M P Q L}$ \\
\hline 10 & 0.0070 & 0.0007 & 0.0004 & 0.2934 & 0.4999 & 0.1986 & 4.6324 & 0.0450 \\
\hline 20 & 0.0164 & 0.0015 & 0.0009 & 0.2828 & 0.4998 & 0.1985 & 3.0617 & 0.0451 \\
\hline 30 & 0.0218 & 0.0020 & 0.0011 & 0.2767 & 0.4998 & 0.1985 & 2.5380 & 0.0451 \\
\hline 40 & 0.0252 & 0.0024 & 0.0013 & 0.2729 & 0.4998 & 0.1984 & 2.2761 & 0.0452 \\
\hline 50 & 0.0274 & 0.0026 & 0.0014 & 0.2704 & 0.4997 & 0.1984 & 2.1190 & 0.0452 \\
\hline 60 & 0.0291 & 0.0027 & 0.0015 & 0.2686 & 0.4997 & 0.1984 & 2.0142 & 0.0452 \\
\hline 70 & 0.0303 & 0.0028 & 0.0016 & 0.2672 & 0.4997 & 0.1984 & 1.9393 & 0.0452 \\
\hline 80 & 0.0312 & 0.0029 & 0.0016 & 0.2661 & 0.4997 & 0.1984 & 1.8832 & 0.0452 \\
\hline 90 & 0.0320 & 0.0030 & 0.0017 & 0.2653 & 0.4997 & 0.1984 & 1.8395 & 0.0452 \\
\hline 100 & 0.0326 & 0.0031 & 0.0017 & 0.2646 & 0.4997 & 0.1984 & 1.8045 & 0.0452 \\
\hline 200 & 0.0355 & 0.0033 & 0.0019 & 0.2613 & 0.4997 & 0.1983 & 1.6472 & 0.0453 \\
\hline 300 & 0.0365 & 0.0034 & 0.0019 & 0.2602 & 0.4997 & 0.1983 & 1.5948 & 0.0453 \\
\hline 400 & 0.0370 & 0.0035 & 0.0019 & 0.2596 & 0.4997 & 0.1983 & 1.5685 & 0.0453 \\
\hline
\end{tabular}


\begin{tabular}{|l|l|l|l|l|l|l|l|l|}
500 & 0.0374 & 0.0035 & 0.0020 & 0.2592 & 0.4996 & 0.1983 & 1.5528 & 0.0453 \\
\hline
\end{tabular} \begin{tabular}{|l|l|l|l|l|l|l|l|l|l|}
\hline 600 & 0.0376 & 0.0035 & 0.0020 & 0.2590 & 0.4996 & 0.1983 & 1.5423 & 0.0453 \\
\hline
\end{tabular} \begin{tabular}{|l|l|l|l|l|l|l|l|l|l|l|}
\hline 700 & 0.0377 & 0.0035 & 0.0020 & 0.2588 & 0.4996 & 0.1983 & 1.5348 & 0.0453 \\
\hline
\end{tabular} \begin{tabular}{|l|l|l|l|l|l|l|l|l|}
\hline 800 & 0.0378 & 0.0036 & 0.0020 & 0.2587 & 0.4996 & 0.1983 & 1.5292 & 0.0453 \\
\hline
\end{tabular} \begin{tabular}{|l|l|l|l|l|l|l|l|l|}
\hline 900 & 0.0379 & 0.0036 & 0.0020 & 0.2586 & 0.4996 & 0.1983 & 1.5248 & 0.0453 \\
\hline
\end{tabular} \begin{tabular}{|l|l|l|l|l|l|l|l|l|l|}
\hline 1000 & 0.0380 & 0.0036 & 0.0020 & 0.2585 & 0.4996 & 0.1983 & 1.5213 & 0.0453 \\
\hline
\end{tabular} \begin{tabular}{|l|l|l|l|l|l|l|l|l|l|}
\hline 2000 & 0.0383 & 0.0036 & 0.0020 & 0.2581 & 0.4996 & 0.1983 & 1.5056 & 0.0453 \\
\hline
\end{tabular} \begin{tabular}{|l|l|l|l|l|l|l|l|l|}
\hline 3000 & 0.0384 & 0.0036 & 0.0020 & 0.2580 & 0.4996 & 0.1983 & 1.5003 & 0.0453 \\
\hline
\end{tabular} \begin{tabular}{|l|l|l|l|l|l|l|l|l|l|l|}
\hline 4000 & 0.0385 & 0.0036 & 0.0020 & 0.2579 & 0.4996 & 0.1983 & 1.4977 & 0.0453 \\
\hline
\end{tabular} \begin{tabular}{|l|l|l|l|l|l|l|l|l|l|}
\hline 5000 & 0.0385 & 0.0036 & 0.0020 & 0.2579 & 0.4996 & 0.1983 & 1.4961 & 0.0453 \\
\hline
\end{tabular} \begin{tabular}{|l|l|l|l|l|l|l|l|l|l|}
\hline 6000 & 0.0386 & 0.0036 & 0.0020 & 0.2579 & 0.4996 & 0.1983 & 1.4951 & 0.0453 \\
\hline
\end{tabular} \begin{tabular}{|l|l|l|l|l|l|l|l|l|l|l|}
\hline 7000 & 0.0386 & 0.0036 & 0.0020 & 0.2579 & 0.4996 & 0.1983 & 1.4943 & 0.0453 \\
\hline
\end{tabular} \begin{tabular}{|l|l|l|l|l|l|l|l|l|l|}
\hline 8000 & 0.0386 & 0.0036 & 0.0020 & 0.2578 & 0.4996 & 0.1983 & 1.4938 & 0.0453 \\
\hline
\end{tabular} \begin{tabular}{|l|l|l|l|l|l|l|l|l|}
\hline 9000 & 0.0386 & 0.0036 & 0.0020 & 0.2578 & 0.4996 & 0.1983 & 1.4933 & 0.0453 \\
\hline
\end{tabular}

Table II: Mean number of customers in the orbit and Mean queue length of high Priority queue for $\lambda_{1}=10 \quad \lambda_{2}=5 \quad \mu_{1}=20 \quad \mu_{2}=25 \quad \mu_{3}=2 \quad \mu_{4}=5 \quad \sigma=100 \quad k=4$ and $\alpha=100$ and various values of $\sigma$

\begin{tabular}{|c|c|c|c|c|c|c|c|c|}
\hline$\sigma$ & $\mathrm{P}_{00}$ & $\mathrm{P}_{10}$ & $\mathrm{P}_{20}$ & $\mathrm{P}_{01}$ & $\mathrm{P}_{11}$ & $\mathrm{P}_{21}$ & $\mathrm{MNCO}$ & $\mathrm{MPQL}$ \\
\hline 10 & 0.0069 & 0.0006 & 0.0004 & 0.2922 & 0.4999 & 0.1999 & 4.6706 & 0.0498 \\
\hline 20 & 0.0163 & 0.0015 & 0.0009 & 0.2817 & 0.4998 & 0.1998 & 3.0913 & 0.0499 \\
\hline 30 & 0.0217 & 0.0020 & 0.0011 & 0.2756 & 0.4998 & 0.1997 & 2.5649 & 0.0499 \\
\hline 40 & 0.0251 & 0.0023 & 0.0013 & 0.2718 & 0.4998 & 0.1997 & 2.3016 & 0.0500 \\
\hline 50 & 0.0273 & 0.0026 & 0.0014 & 0.2693 & 0.4997 & 0.1997 & 2.1436 & 0.0500 \\
\hline 60 & 0.0289 & 0.0027 & 0.0015 & 0.2675 & 0.4997 & 0.1996 & 2.0382 & 0.0500 \\
\hline 70 & 0.0301 & 0.0028 & 0.0016 & 0.2661 & 0.4997 & 0.1996 & 1.9630 & 0.0501 \\
\hline 80 & 0.0311 & 0.0029 & 0.0016 & 0.2651 & 0.4997 & 0.1996 & 1.9065 & 0.0501 \\
\hline 90 & 0.0318 & 0.0030 & 0.0017 & 0.2642 & 0.4997 & 0.1996 & 1.8626 & 0.0501 \\
\hline 100 & 0.0324 & 0.0030 & 0.0017 & 0.2635 & 0.4997 & 0.1996 & 1.8275 & 0.0501 \\
\hline 200 & 0.0353 & 0.0033 & 0.0018 & 0.2603 & 0.4997 & 0.1996 & 1.6693 & 0.0501 \\
\hline 300 & 0.0364 & 0.0034 & 0.0019 & 0.2591 & 0.4997 & 0.1996 & 1.6166 & 0.0501 \\
\hline 400 & 0.0369 & 0.0035 & 0.0019 & 0.2585 & 0.4997 & 0.1996 & 1.5902 & 0.0501 \\
\hline 500 & 0.0372 & 0.0035 & 0.0019 & 0.2581 & 0.4996 & 0.1996 & 1.5744 & 0.0501 \\
\hline 600 & 0.0374 & 0.0035 & 0.0020 & 0.2579 & 0.4996 & 0.1996 & 1.5638 & 0.0501 \\
\hline 700 & 0.0376 & 0.0035 & 0.0020 & 0.2577 & 0.4996 & 0.1996 & 1.5563 & 0.0501 \\
\hline 800 & 0.0377 & 0.0035 & 0.0020 & 0.2576 & 0.4996 & 0.1996 & 1.5507 & 0.0502 \\
\hline 900 & 0.0378 & 0.0035 & 0.0020 & 0.2575 & 0.4996 & 0.1996 & 1.5463 & 0.0502 \\
\hline 1000 & 0.0378 & 0.0036 & 0.0020 & 0.2574 & 0.4996 & 0.1996 & 1.5427 & 0.0502 \\
\hline
\end{tabular}

$|2000| 0.0382|0.0036| 0.0020|0.2571| 0.4996|0.1995| 1.5269 \mid 0.0502$ \begin{tabular}{|l|l|l|l|l|l|l|l|l|l|l|}
\hline 3000 & 0.0383 & 0.0036 & 0.0020 & 0.2569 & 0.4996 & 0.1995 & 1.5216 & 0.0502 \\
\hline
\end{tabular} \begin{tabular}{|l|l|l|l|l|l|l|l|l|}
\hline 4000 & 0.0383 & 0.0036 & 0.0020 & 0.2569 & 0.4996 & 0.1995 & 1.5190 & 0.0502 \\
\hline
\end{tabular} \begin{tabular}{|l|l|l|l|l|l|l|l|l|l|}
\hline 5000 & 0.0384 & 0.0036 & 0.0020 & 0.2568 & 0.4996 & 0.1995 & 1.5174 & 0.0502 \\
\hline
\end{tabular} \begin{tabular}{|l|l|l|l|l|l|l|l|l|}
\hline 6000 & 0.0384 & 0.0036 & 0.0020 & 0.2568 & 0.4996 & 0.1995 & 1.5164 & 0.0502 \\
\hline
\end{tabular} \begin{tabular}{|l|l|l|l|l|l|l|l|l|l|}
\hline 7000 & 0.0384 & 0.0036 & 0.0020 & 0.2568 & 0.4996 & 0.1995 & 1.5156 & 0.0502 \\
\hline
\end{tabular} \begin{tabular}{|l|l|l|l|l|l|l|l|l|l|}
\hline 8000 & 0.0384 & 0.0036 & 0.0020 & 0.2568 & 0.4996 & 0.1995 & 1.5150 & 0.0502 \\
\hline
\end{tabular} \begin{tabular}{|l|l|l|l|l|l|l|l|l|}
\hline 9000 & 0.0384 & 0.0036 & 0.0020 & 0.2568 & 0.4996 & 0.1995 & 1.5146 & 0.0502 \\
\hline
\end{tabular}

Table III: Mean number of customers in the orbit and Mean queue length of high Priority queue for $\lambda_{1}=10 \quad \lambda_{2}=5 \quad \mu_{1}=20 \quad \mu_{2}=25 \quad \mu_{3}=2 \quad \mu_{4}=5 \quad \sigma=100 \quad k=6$ and $\alpha=100$ and various values of $\sigma$

\begin{tabular}{|c|c|c|c|c|c|c|c|c|}
\hline$\sigma$ & $\mathrm{P}_{00}$ & $\mathrm{P}_{10}$ & $\mathrm{P}_{20}$ & $\mathrm{P}_{01}$ & $\mathrm{P}_{11}$ & $\mathrm{P}_{21}$ & $\mathrm{MNCO}$ & $\mathrm{MPQL}$ \\
\hline 10 & 0.0069 & 0.0006 & 0.0004 & 0.2922 & 0.4999 & 0.1999 & 4.6725 & 0.0501 \\
\hline 20 & 0.0163 & 0.0015 & 0.0009 & 0.2816 & 0.4998 & 0.1998 & 3.0928 & 0.0502 \\
\hline 30 & 0.0217 & 0.0020 & 0.0011 & 0.2755 & 0.4998 & 0.1998 & 2.5663 & 0.0503 \\
\hline 40 & 0.0251 & 0.0023 & 0.0013 & 0.2718 & 0.4998 & 0.1997 & 2.3030 & 0.0503 \\
\hline 50 & 0.0273 & 0.0026 & 0.0014 & 0.2692 & 0.4997 & 0.1997 & 2.1449 & 0.0503 \\
\hline 60 & 0.0289 & 0.0027 & 0.0015 & 0.2674 & 0.4997 & 0.1997 & 2.0395 & 0.0504 \\
\hline 70 & 0.0301 & 0.0028 & 0.0016 & 0.2661 & 0.4997 & 0.1997 & 1.9642 & 0.0504 \\
\hline 80 & 0.0311 & 0.0029 & 0.0016 & 0.2650 & 0.4997 & 0.1997 & 1.9078 & 0.0504 \\
\hline 90 & 0.0318 & 0.0030 & 0.0017 & 0.2642 & 0.4997 & 0.1997 & 1.8639 & 0.0504 \\
\hline 100 & 0.0324 & 0.0030 & 0.0017 & 0.2635 & 0.4997 & 0.1997 & 1.8287 & 0.0504 \\
\hline 200 & 0.0353 & 0.0033 & 0.0018 & 0.2602 & 0.4997 & 0.1996 & 1.6705 & 0.0504 \\
\hline 300 & 0.0364 & 0.0034 & 0.0019 & 0.2591 & 0.4997 & 0.1996 & 1.6178 & 0.0505 \\
\hline 400 & 0.0369 & 0.0035 & 0.0019 & 0.2585 & 0.4997 & 0.1996 & 1.5914 & 0.0505 \\
\hline 500 & 0.0372 & 0.0035 & 0.0019 & 0.2581 & 0.4996 & 0.1996 & 1.5756 & 0.0505 \\
\hline 600 & 0.0374 & 0.0035 & 0.0020 & 0.2579 & 0.4996 & 0.1996 & 1.5650 & 0.0505 \\
\hline 700 & 0.0376 & 0.0035 & 0.0020 & 0.2577 & 0.4996 & 0.1996 & 1.5575 & 0.0505 \\
\hline 800 & 0.0377 & 0.0035 & 0.0020 & 0.2576 & 0.4996 & 0.1996 & 1.5518 & 0.0505 \\
\hline 900 & 0.0378 & 0.0035 & 0.0020 & 0.2575 & 0.4996 & 0.1996 & 1.5474 & 0.0505 \\
\hline
\end{tabular}


$|1000| 0.0378|0.0036| 0.0020|0.2574| 0.4996|0.1996| 1.5439 \mid 0.0505$ \begin{tabular}{|l|l|l|l|l|l|l|l|l|l|}
\hline 2000 & 0.0382 & 0.0036 & 0.0020 & 0.2570 & 0.4996 & 0.1996 & 1.5281 & 0.0505 \\
\hline
\end{tabular} \begin{tabular}{|l|l|l|l|l|l|l|l|l|l|l|}
\hline 3000 & 0.0383 & 0.0036 & 0.0020 & 0.2569 & 0.4996 & 0.1996 & 1.5228 & 0.0505 \\
\hline
\end{tabular} \begin{tabular}{|l|l|l|l|l|l|l|l|l|}
\hline 4000 & 0.0383 & 0.0036 & 0.0020 & 0.2568 & 0.4996 & 0.1996 & 1.5202 & 0.0505
\end{tabular} \begin{tabular}{|l|l|l|l|l|l|l|l|l|}
5000 & 0.0384 & 0.0036 & 0.0020 & 0.2568 & 0.4996 & 0.1996 & 1.5186 & 0.0505 \\
\hline
\end{tabular} \begin{tabular}{|l|l|l|l|l|l|l|l|l|}
\hline 6000 & 0.0384 & 0.0036 & 0.0020 & 0.2568 & 0.4996 & 0.1996 & 1.5175 & 0.0505 \\
\hline
\end{tabular} \begin{tabular}{|l|l|l|l|l|l|l|l|l||}
7000 & 0.0384 & 0.0036 & 0.0020 & 0.2567 & 0.4996 & 0.1996 & 1.5168 & 0.0505
\end{tabular} \begin{tabular}{|l|l|l|l|l|l|l|l|l|l|}
\hline 8000 & 0.0384 & 0.0036 & 0.0020 & 0.2567 & 0.4996 & 0.1996 & 1.5162 & 0.0505 \\
\hline
\end{tabular} \begin{tabular}{|l|l|l|l|l|l|l|l|l|l|}
\hline 9000 & 0.0384 & 0.0036 & 0.0020 & 0.2567 & 0.4996 & 0.1996 & 1.5158 & 0.0505 \\
\hline
\end{tabular}

Table IV: Mean number of customers in the orbit and Mean queue length of high Priority queue for $\begin{array}{llllllll}\lambda_{1}=10 & \lambda_{2}=5 & \mu_{1}=20 & \mu_{2}=25 & \mu_{3}=2 & \mu_{4}=5 & \sigma=100 & \mathrm{k}=8\end{array}$ and $\alpha=100$ and various values of $\sigma$

\begin{tabular}{|c|c|c|c|c|c|c|c|c|}
\hline$\sigma$ & $\mathrm{P}_{00}$ & $\mathrm{P}_{10}$ & $\mathrm{P}_{20}$ & $\mathrm{P}_{01}$ & $\mathrm{P}_{11}$ & $\mathrm{P}_{21}$ & $\mathrm{MNCO}$ & $\mathrm{MPQL}$ \\
\hline 10 & 0.0069 & 0.0006 & 0.0004 & 0.2922 & 0.4999 & 0.1999 & 4.6726 & 0.0501 \\
\hline 20 & 0.0163 & 0.0015 & 0.0009 & 0.2816 & 0.4998 & 0.1998 & 3.0929 & 0.0502 \\
\hline 30 & 0.0217 & 0.0020 & 0.0011 & 0.2755 & 0.4998 & 0.1998 & 2.5664 & 0.0503 \\
\hline 40 & 0.0251 & 0.0023 & 0.0013 & 0.2718 & 0.4998 & 0.1997 & 2.3030 & 0.0503 \\
\hline 50 & 0.0273 & 0.0026 & 0.0014 & 0.2692 & 0.4997 & 0.1997 & 2.1450 & 0.0504 \\
\hline 60 & 0.0289 & 0.0027 & 0.0015 & 0.2674 & 0.4997 & 0.1997 & 2.0396 & 0.0504 \\
\hline 70 & 0.0301 & 0.0028 & 0.0016 & 0.2661 & 0.4997 & 0.1997 & 1.9643 & 0.0504 \\
\hline 80 & 0.0311 & 0.0029 & 0.0016 & 0.2650 & 0.4997 & 0.1997 & 1.9078 & 0.0504 \\
\hline 90 & 0.0318 & 0.0030 & 0.0017 & 0.2642 & 0.4997 & 0.1997 & 1.8639 & 0.0504 \\
\hline 100 & 0.0324 & 0.0030 & 0.0017 & 0.2635 & 0.4997 & 0.1997 & 1.8288 & 0.0504 \\
\hline 200 & 0.0353 & 0.0033 & 0.0018 & 0.2602 & 0.4997 & 0.1996 & 1.6706 & 0.0505 \\
\hline 300 & 0.0364 & 0.0034 & 0.0019 & 0.2591 & 0.4997 & 0.1996 & 1.6178 & 0.0505 \\
\hline 400 & 0.0369 & 0.0035 & 0.0019 & 0.2585 & 0.4997 & 0.1996 & 1.5915 & 0.0505 \\
\hline 500 & 0.0372 & 0.0035 & 0.0019 & 0.2581 & 0.4996 & 0.1996 & 1.5756 & 0.0505 \\
\hline 600 & 0.0374 & 0.0035 & 0.0020 & 0.2579 & 0.4996 & 0.1996 & 1.5651 & 0.0505 \\
\hline 700 & 0.0376 & 0.0035 & 0.0020 & 0.2577 & 0.4996 & 0.1996 & 1.5576 & 0.0505 \\
\hline 800 & 0.0377 & 0.0035 & 0.0020 & 0.2576 & 0.4996 & 0.1996 & 1.5519 & 0.0505 \\
\hline
\end{tabular}

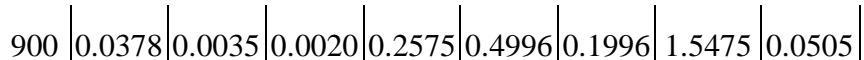
\begin{tabular}{|l|l|l|l|l|l|l|l|l|l|}
\hline 1000 & 0.0378 & 0.0036 & 0.0020 & 0.2574 & 0.4996 & 0.1996 & 1.5440 & 0.0505 \\
\hline
\end{tabular} \begin{tabular}{|l|l|l|l|l|l|l|l|l|}
\hline 2000 & 0.0382 & 0.0036 & 0.0020 & 0.2570 & 0.4996 & 0.1996 & 1.5282 & 0.0505 \\
\hline
\end{tabular} \begin{tabular}{|l|l|l|l|l|l|l|l|l|l|}
\hline 3000 & 0.0383 & 0.0036 & 0.0020 & 0.2569 & 0.4996 & 0.1996 & 1.5229 & 0.0505 \\
\hline
\end{tabular} \begin{tabular}{|l|l|l|l|l|l|l|l|l|}
\hline 4000 & 0.0383 & 0.0036 & 0.0020 & 0.2568 & 0.4996 & 0.1996 & 1.5202 & 0.0505 \\
\hline
\end{tabular} \begin{tabular}{|l|l|l|l|l|l|l|l|l|l|}
\hline 5000 & 0.0384 & 0.0036 & 0.0020 & 0.2568 & 0.4996 & 0.1996 & 1.5187 & 0.0505 \\
\hline
\end{tabular}

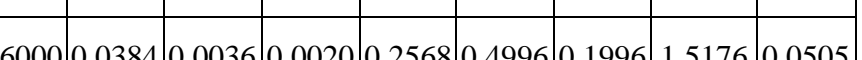
\begin{tabular}{|l|l|l|l|l|l|l|l|l|}
6000 & 0.0384 & 0.0036 & 0.0020 & 0.2568 & 0.4996 & 0.1996 & 1.5176 & 0.0505 \\
\hline
\end{tabular}

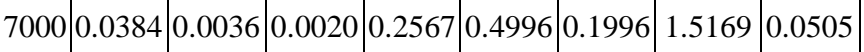
\begin{tabular}{|l|l|l|l|l|l|l|l|l|}
\hline 8000 & 0.0384 & 0.0036 & 0.0020 & 0.2567 & 0.4996 & 0.1996 & 1.5163 & 0.0505 \\
\hline
\end{tabular} \begin{tabular}{|l|l|l|l|l|l|l|l|l|}
\hline 9000 & 0.0384 & 0.0036 & 0.0020 & 0.2567 & 0.4996 & 0.1996 & 1.5158 & 0.0505 \\
\hline
\end{tabular}

Table V: Mean number of customers in the orbit and Mean queue length of high Priority queue for $\lambda_{1}=10 \quad \lambda_{2}=5 \quad \mu_{1}=20 \quad \mu_{2}=25 \quad \mu_{3}=2 \quad \mu_{4}=5 \quad \sigma=100 \quad k=5$ $\sigma=100$ and various values of $\alpha$

\begin{tabular}{|c|c|c|c|c|c|c|c|c|}
\hline$\alpha$ & $\mathbf{P}_{\mathbf{0 0}}$ & $\mathbf{P}_{\mathbf{1 0}}$ & $\mathbf{P}_{\mathbf{2 0}}$ & $\mathbf{P}_{\mathbf{0 1}}$ & $\mathbf{P}_{\mathbf{1 1}}$ & $\mathbf{P}_{\mathbf{2 1}}$ & $\mathrm{MNCO}$ & $\mathrm{MPQL}$ \\
\hline 100 & 0.0324 & 0.0030 & 0.0017 & 0.2635 & 0.4997 & 0.1997 & 1.8285 & 0.0503 \\
\hline 200 & 0.0176 & 0.0008 & 0.0004 & 0.2813 & 0.4999 & 0.1999 & 1.8193 & 0.0500 \\
\hline 300 & 0.0120 & 0.0004 & 0.0002 & 0.2875 & 0.5000 & 0.1999 & 1.8176 & 0.0500 \\
\hline 400 & 0.0091 & 0.0002 & 0.0001 & 0.2906 & 0.5000 & 0.2000 & 1.8170 & 0.0499 \\
\hline 500 & 0.0074 & 0.0001 & 0.0001 & 0.2925 & 0.5000 & 0.2000 & 1.8167 & 0.0499 \\
\hline 600 & 0.0062 & 0.0001 & 0.0001 & 0.2937 & 0.5000 & 0.2000 & 1.8166 & 0.0499 \\
\hline 700 & 0.0053 & 0.0001 & 0.0000 & 0.2946 & 0.5000 & 0.2000 & 1.8165 & 0.0499 \\
\hline 800 & 0.0047 & 0.0001 & 0.0000 & 0.2953 & 0.5000 & 0.2000 & 1.8164 & 0.0499 \\
\hline 900 & 0.0041 & 0.0000 & 0.0000 & 0.2958 & 0.5000 & 0.2000 & 1.8164 & 0.0499 \\
\hline 1000 & 0.0037 & 0.0000 & 0.0000 & 0.2962 & 0.5000 & 0.2000 & 1.8163 & 0.0499 \\
\hline 1100 & 0.0034 & 0.0000 & 0.0000 & 0.2966 & 0.5000 & 0.2000 & 1.8163 & 0.0499 \\
\hline 1200 & 0.0031 & 0.0000 & 0.0000 & 0.2969 & 0.5000 & 0.2000 & 1.8163 & 0.0499 \\
\hline
\end{tabular}




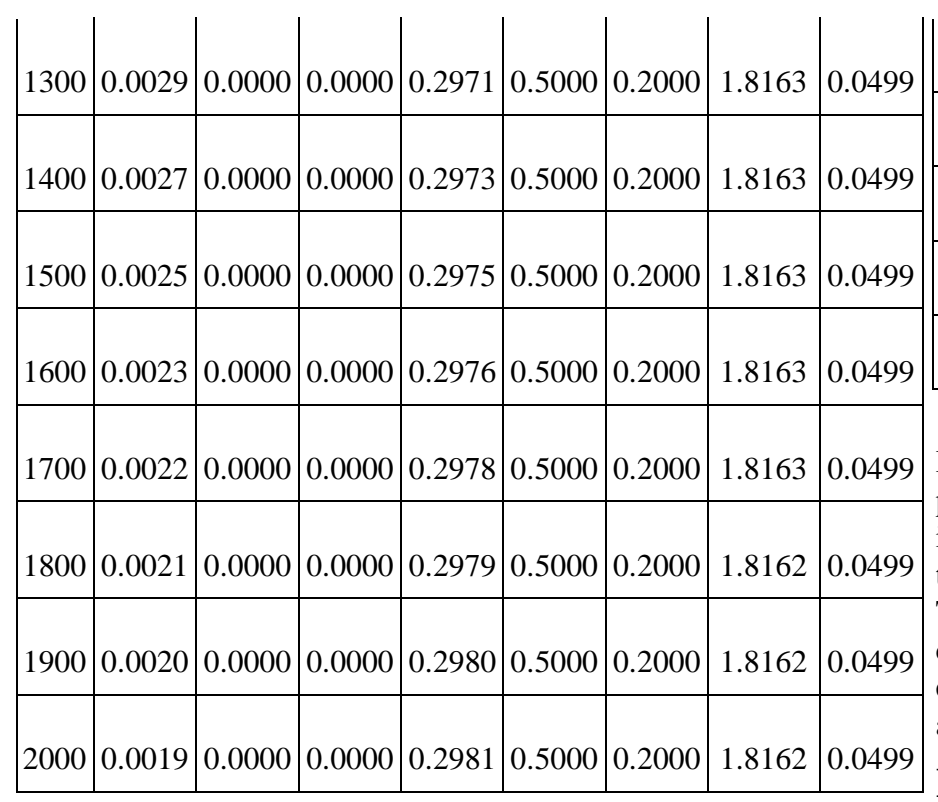

Table VI: Mean number of customers in the orbit and Mean queue length of high Priority queue for $\lambda_{1}=10 \quad \lambda_{2}=5 \quad \mu_{1}=20 \quad \mu_{2}=25 \quad \mu_{3}=2 \quad \mu_{4}=5 \quad \sigma=100 \quad \mathrm{k}=5$, $\sigma=1000$ and various values of $\alpha$

\begin{tabular}{|c|c|c|c|c|c|c|c|c|}
\hline$\alpha$ & $\mathbf{P}_{\mathbf{0 0}}$ & $\mathbf{P}_{\mathbf{1 0}}$ & $\mathbf{P}_{\mathbf{2 0}}$ & $\mathbf{P}_{\mathbf{0 1}}$ & $\mathbf{P}_{\mathbf{1 1}}$ & $\mathbf{P}_{\mathbf{2 1}}$ & $\mathbf{M N C O}$ & $\mathbf{M P Q L}$ \\
\hline 100 & 0.0378 & 0.0036 & 0.0020 & 0.2574 & 0.4996 & 0.1996 & 1.5437 & 0.0504 \\
\hline 200 & 0.0205 & 0.0010 & 0.0005 & 0.2782 & 0.4999 & 0.1999 & 1.5344 & 0.0500 \\
\hline 300 & 0.0140 & 0.0005 & 0.0002 & 0.2854 & 0.5000 & 0.1999 & 1.5327 & 0.0500 \\
\hline 400 & 0.0106 & 0.0003 & 0.0001 & 0.2890 & 0.5000 & 0.2000 & 1.5321 & 0.0499 \\
\hline 500 & 0.0086 & 0.0002 & 0.0001 & 0.2912 & 0.5000 & 0.2000 & 1.5318 & 0.0499 \\
\hline 600 & 0.0072 & 0.0001 & 0.0001 & 0.2927 & 0.5000 & 0.2000 & 1.5316 & 0.0499 \\
\hline 700 & 0.0062 & 0.0001 & 0.0000 & 0.2937 & 0.5000 & 0.2000 & 1.5315 & 0.0499 \\
\hline 800 & 0.0054 & 0.0001 & 0.0000 & 0.2945 & 0.5000 & 0.2000 & 1.5315 & 0.0499 \\
\hline 900 & 0.0048 & 0.0001 & 0.0000 & 0.2951 & 0.5000 & 0.2000 & 1.5314 & 0.0499 \\
\hline 1000 & 0.0044 & 0.0000 & 0.0000 & 0.2956 & 0.5000 & 0.2000 & 1.5314 & 0.0499 \\
\hline 1100 & 0.0040 & 0.0000 & 0.0000 & 0.2960 & 0.5000 & 0.2000 & 1.5314 & 0.0499 \\
\hline 1200 & 0.0036 & 0.0000 & 0.0000 & 0.2963 & 0.5000 & 0.2000 & 1.5314 & 0.0499 \\
\hline 1300 & 0.0034 & 0.0000 & 0.0000 & 0.2966 & 0.5000 & 0.2000 & 1.5313 & 0.0499 \\
\hline 1400 & 0.0031 & 0.0000 & 0.0000 & 0.2969 & 0.5000 & 0.2000 & 1.5313 & 0.0499 \\
\hline 1500 & 0.0029 & 0.0000 & 0.0000 & 0.2971 & 0.5000 & 0.2000 & 1.5313 & 0.0499 \\
\hline
\end{tabular}

\begin{tabular}{|l|l|l|l|l|l|l|l|l|}
\hline 1600 & 0.0027 & 0.0000 & 0.0000 & 0.2973 & 0.5000 & 0.2000 & 1.5313 & 0.0499 \\
\hline 1700 & 0.0026 & 0.0000 & 0.0000 & 0.2974 & 0.5000 & 0.2000 & 1.5313 & 0.0499 \\
\hline 1800 & 0.0024 & 0.0000 & 0.0000 & 0.2976 & 0.5000 & 0.2000 & 1.5313 & 0.0499 \\
\hline 1900 & 0.0023 & 0.0000 & 0.0000 & 0.2977 & 0.5000 & 0.2000 & 1.5313 & 0.0499 \\
\hline 2000 & 0.0022 & 0.0000 & 0.0000 & 0.2978 & 0.5000 & 0.2000 & 1.5313 & 0.0499 \\
\hline
\end{tabular}

10. CONCLUSIONS

It is observed from the numerical study that Mean number of low priority customers in the orbit decreases as the retrial rate increases. The probabilities for the server being idle, busy during the working vacation and normal period depend on retrial rate. The various special cases discussed in section 7 are particular cases of this research work. This research work can further be extended by introducing various parameters like negative arrival and second optional services.

\section{References}

[1] Artalejo .J.R. A classified bibliography of research on retrial queues Progress in 1990-1999, Top 7, pp.187-211, 1999.

[2] Choi B.D and Y. Chang. Single server retrial queues with priority calls, Mathematical and Computer Modeling, 30, No. 3-4, pp.7-32, 1999.

[3] Falin G.I, Artalejo J.R, Martin. M .On the single server retrial queue with priority customers, Queueing systems 14, pp. 439-455, 1993.

[4] Gomez-Corral. A, Analysis of Single server retrial queue with quasi random input and non-pre-emptive priority, Computers and Mathematics with Applications, Vol 43,No.6-7, pp 767-882,2002

[5] G.Ayyappan, A. Muthu Ganapathi Subramanian and Gopal sekar. M/M/1 Retrial Queueing System with pre-emptive priority Service and Single Vacation - Exhaustive Service, Pacific Asian Journal of Mathematics,Vo1 3, No.1-2, pp.307-322, 2009 .

[6] Liu. W, Xu .X and Tian. N. Some results on the M/M/1 queue with working vacation, Operation Research Letters, Vol 35, No.5, pp 595-600, 2007.

[7] Servi L.D and S.G. Finn. M/M/1 queue with working vacation, Performance evaluations, Vol.50, No.1, pp 4152, 2002.

[8] Tian. N, Zhao. $\mathrm{X}$ and Wang. $\mathrm{K}$. The $\mathrm{M} / \mathrm{M} / 1$ queue with single working vacation, International Journal of Information and Management Science, Vol.19, No.4, pp 621-634, 2008.

[9] Tien Van Do. M/M/1 retrial queue with working vacation, Acta Informatica, Vol 47, No.1, pp 67-75, 2009.

[10] Wu. D and Takagi. H. M/G/1 queue with Multiple working vacation, Performance Evaluation, Vol.63,issue 7, pp 654-681, 2006. 